\title{
ALGUMAS CONSIDERAÇÕES SOBRE A IMPORTÂNCIA DA REPRESENTAÇÃO DE RAÇA, GÊNERO E CLASSE SOCIAL EM UM LIVRO DE ESPANHOL
}

\author{
SOME CONSIDERATIONS ABOUT THE \\ IMPORTANCE OF RACE, GENDER AND SOCIAL \\ CLASS REPRESENTATION IN A SPANISH BOOK
}

\author{
Letícia Camargo Ferreira Netto* \\ Keila de Oliveira** \\ Aparecida de Jesus Ferreira***
}

\begin{abstract}
Resumo: Este artigo apresenta algumas considerações sobre a representação das imagens em relação à raça, gênero e classe social do livro didático de Espanhol $1^{\circ}$ Libro do Ensino Médio, da coleção Síntesis (IVAN MARTÍN, 2010). O interesse desse estudo se deu através de discussões e reflexões durante uma disciplina² do Mestrado sobre a importância de analisar o livro didático como instrumento pedagógico. Tal discussão nos possibilitou refletir sobre "Qual a relevância das representações visuais em relação à raça, gênero e classe social encontradas em um livro didático de Espanhol?”, sendo essa nossa pergunta de pesquisa. Para nos dar suporte, partimos do estudo da Lei 10.639/03 e sua importância na área educacional e de outras pesquisas, conforme Ferreira (2014), que apresenta reflexões sobre as políticas do livro didático e também suas contribuições sobre as identidades sociais de raça, gênero, sexualidade e classe
\end{abstract}

\footnotetext{
${ }^{1}$ Este artigo foi enviado para os anais do CIEL (Congresso Internacional de Estudos em Linguagem) em uma forma simplificada.

"Mestranda em Estudos da Linguagem/UEPG. Graduação - Faculdades Integradas de Itararé (2010), professora de espanhol do Instituto de Idiomas Yázigi, Professora de espanhol e Língua Portuguesa no ensino médio e técnico do Centro Estadual de Educação Tecnológica Paula Souza, Professora de Espanhol no Centro de Estudos de Línguas- peb.II - cat.o - Secretaria da Estado da Educação do Estado de São Paulo. Email: leticia_almeida88@hotmail.com.

"t"Graduada em Pedagogia (UEPG) Mestre em Estudos da Linguagem- Área de concentração: Linguagem, Identidade e Subjetividade (UEPG). Email: keilakdn@gmail.com

**** Pós doutorado e doutorado - Universidade de Londres - Inglaterra, mestrado - Universidade Estadual Paulista Júlio de Mesquita Filho. Professora associada da UEPG - docente permanente do programa de Mestrado em Linguagem - UEPG. E-mail: aparecidadejesusferreira@gmail.com

${ }^{2}$ Disciplina de "Formação de professoras/es de Línguas, Identidade Profissional e Letramento Racial" ofertada pelo Programa de Pós-graduação em Estudos da Linguagem (Mestrado) na Universidade Estadual de Ponta Grossa, ministrado pela Profa. Dra. Aparecida de Jesus Ferreira.
} 
em livros didáticos. A metodologia utilizada foi análise documental e bibliográfica. As questões abordadas neste artigo a partir da análise das imagens do livro didático Sintesis são relevantes por possibilitar que professores/as reflitam sobre o ensino/ aprendizagem de língua estrangeira em uma perspectiva positiva quando relacionada à raça, gênero e classe social, contribuindo para a desconstrução de estereótipos que denotem ideologias expressas em conceitos de racismo, preconceito e discriminação. PaLAVRAS-CHAVE: Representatividade de raça, gênero e classe; Línguas Estrangeiras Modernas; Análise de livro didático; Língua Espanhola.

ABstract: This paper presents some considerations about the representation of images in relation to race, gender and social class of the Spanish textbook $1^{\circ}$ Libro do Ensino Médio from the collection: Sintesis (IVAN MARTÍN, 2010). The interest of this study was through discussions and reflections during a Master's course on the importance of analyzing the textbook as a pedagogical instrument. This discussion allowed us to reflect on "What is the relevance of visual representations in relation to race, gender and social class found in a Spanish textbook?", which is our research question. To support us, we start from the study of Law 10.639 / 03 and its importance in the educational area and other research, such as Ferreira (2014), who presents reflections on the textbook policies and their contributions on the social identities of race, gender, sexuality and class in textbooks. The methodology used was documentary and bibliographical analysis. The issues addressed in this paper from the analysis of the images in textbook Sintesis are relevant for enabling teachers to reflect on foreign language teaching / learning in a positive perspective when related to race, gender and social class contributing to the deconstruction of stereotypes denoting ideologies expressed in concepts of racism, prejudice and discrimination.

KEYWORDs: Representativity of race, gender and social class; Modern Foreign Languages; Textbook analysis; Spanish language.

\section{INTRODUÇÃO}

Atualmente, a preocupação em discutir as questões que abordam a igualdade de direitos sociais, buscando atender, entre outros, a demanda de questões raciais, de gênero e classe social, tem sido pauta de diversas pesquisas e de movimentos sociais, e conquistado cada vez mais novos adeptos e defensores, principalmente pelas conquistas obtidas através da luta e resistência dos movimentos sociais e pela relevância de aprofundamento de estudos que buscam compreender de que maneira as medidas socioeducativas podem intervir para neutralizar as marcas deixadas pelo preconceito e pela discriminação e assim caminhar, mesmo que a passos lentos, para uma sociedade com princípios de igualdade.

Nesse sentido, esse artigo busca refletir sobre a possibilidade de discutir sobre raça e gênero no espaço escolar, pois entendemos que a escola pode contribuir significativamente 
na formação dos educandos, pelo fato de ser um espaço dinâmico de aprendizado. Assim, buscamos discutir nesse artigo como o livro didático, enquanto um dos materiais pedagógicos mais utilizados em sala de aula, pode contribuir para discussões a respeito de raça, gênero e classe social. Partimos do estudo de Jorge (2014, p. 73-78), ao analisar as discussões sobre o PNLD, em que traz a perspectiva de construção de identidades positivas a partir do uso do livro didático, afirmando que são múltiplas as identidades dos estudantes da educação básica e essas identidades "podem e precisam ser exploradas nos processos educativos".

Assim, o objetivo deste artigo é discutir sobre a representação das identidades sociais de raça, gênero e classe social presentes no livro didático (LD) na Língua estrangeira (LE), por meio das imagens. O interesse em perceber como o LD apresenta essas identidades surgiu durante as discussões e reflexões sobre a importância de analisar o livro didático como instrumento pedagógico na disciplina de "Formação de professoras/es de Línguas, Identidade Profissional e Letramento Racial" do mestrado em Estudos da Linguagem da Universidade Estadual de Ponta Grossa, ministrado pela Profa. Dra. Aparecida de Jesus Ferreira. Tal discussão nos permitiu refletir sobre "Qual a relevância das representações visuais em relação à raça, gênero e classe social encontradas em um livro didático?”.

Para Norton e Toohey (2002, p. 115), "[...] a língua não é apenas um sistema linguístico de signos e símbolos, mas também uma prática social complexa de atribuição de valor e significado a quem fala" (p. 115). Sendo assim, as aulas de língua estrangeira são instrumentos de construção de sentidos que vão muito além da aprendizagem da língua, estabelecendo uma relação entre a linguagem e as questões sociais de poder, de identidades e de diversidade. Dentro dessa perspectiva, o ensino de línguas configura-se como uma possibilidade do professor inserir discussões de diversas temáticas em sala de aula.

A motivação deste estudo sobre identidades sociais de raça e gênero no livro didático é que essas identidades nem sempre são contempladas, distanciando a realidade em que o aluno/a vive, afetando na construção de identidade dos discentes. Principalmente levando em consideração tais questões:

[...] Busca-se conectar com as questões de gênero, classe, sexualidade, raça, etnia, cultura, identidade, política, ideologia e discurso. E, fundamentalmente, torna-se uma dinâmica que abre novas questões que surgem a partir deste conjunto. (PENNYCOOK, 2001, p. 10 apud FERREIRA, 2014, p. 95).

Diante disso, se torna relevante que análises do livro didático sejam realizadas pelo professor/a, pois Ferreira (2014, p. 143-158) revela que as questões de identidades sociais de classe são raramente abordadas pelas pesquisas e, quando abordadas, apresentam em maior proporção pessoas de poder aquisitivo elevado e em menor, de pessoas pobres. Ainda assim, quando essas aparecem é de maneira estereotipada. O mesmo ocorre com as identidades 
de gênero e de raça nos LD de inglês, que permanecem a reproduzir estereótipos. Por isso, torna-se imprescindível o papel do professor/a de levar os discentes a refletir sobre as possíveis ideologias por detrás das imagens, questionando e aprendendo a construir a criticidade.

Dambros (2016, p.14) destaca ainda que o livro didático é utilizado pela maioria dos professores, não como um apoio durante as aulas, mas na maioria das vezes como único material de ensino em sala de aula. Nesse sentido, a autora traz a questão do livro didático ser visto como fonte segura de informações, o que nem sempre é real, ressaltando ainda que "o LD precisa ser utilizado apenas como um suporte, sendo visto e utilizado de forma crítica, desmascarando-se as ideologias de que ele é portador".

Segundo Norton e Toohey (2011, p. 412-446), as pesquisas com foco em identidade são muito importantes por possibilitarem lançar luz sobre as maneiras como se dão as relações sociais nos contextos de ensino e aprendizagem de línguas. Nessa perspectiva, o presente trabalho pretende discutir sobre a relevância das representações visuais em relação à raça e gênero no livro didático.

Essa pesquisa tem caráter bibliográfico e está estruturada em tópicos: a importância do livro didático de Espanhol para o ensino da Língua Estrangeira; A contribuição do LD na formação humana dos alunos no que se refere à (re)construção da identidade social de raça, gênero, e classe social. E por fim, alguns apontamentos sobre as imagens contidas no LD, de Espanhol, 1ํ Libro do Ensino Médio, da coleção Síntesis (Ivan Martín, 2010) e as considerações finais.

\section{Discussão TEÓRICA}

\section{A IMPORTÂNCIA DO LIVRO DIDÁTICO DE ESPANHOL PARA O ENSINO DE LÍNGUA EsTRANGEIRA}

A implantação gratuita pela primeira vez dos LD de línguas estrangeiras nas escolas públicas de nosso país ocorreu em 2011, pelo Programa Nacional do Livro Didático (PNLD, doravante). Segundo Ferreira (2014), até então, os/as professores/as dessa disciplina “[...] faziam uma compilação de diversos livros didáticos para ter como seu próprio material de ensino ou produziam os seus próprios e utilizavam nas aulas com seus alunos ou então solicitavam que os alunos comprassem LD produzidos no Brasil [...]" (p. 93). Desse modo, de acordo a autora, "essa política de implantação do uso do livro didático de língua estrangeira tem sido considerada um avanço para o ensino de língua estrangeira nas escolas públicas no Brasil [...]” (p. 93).

O livro didático, segundo Vigotsky (2000), é um “artefato de mediação" que, como uma das ferramentas de apoio para o professor/a, contribui para suprir as necessidades de aprendizagem dos alunos. Para que isso ocorra efetivamente, porém, é preciso considerar o contexto histórico e social em que as/os alunas/os estão inseridas/os.

Diante dessa afirmativa, torna-se imprescindível o docente ter um olhar crítico e uma preocupação em relação aos livros didáticos utilizados como meio de ensino - aprendizagem 
e seu impacto na construção de identidade dos discentes. Pois, como afirma Dambros (2016, p. 35) [...] "ao ensinar uma língua é necessário pensar num cidadão completo", a autora destaca ainda que (...) "a proficiência na língua não é o fator mais importante, antes dele existe a questão do conhecimento cultural, de mundo, de sociedade e de criticidade, para que o aluno aprenda não apenas aceitar, tudo o que é imposto". (DAMBROS, 2016, p. 36)

Assim, ao discutirmos sobre a relevância do livro didático enquanto material pedagógico, não estamos apenas nos referindo ao ensino-aprendizagem da língua espanhola, e sim como esse material pode contribuir na formação identitária dos educandos de maneira positiva.

A CONTRIBUIÇÃO DO LD NA FORMAÇÃO HUMANA DOS ALUNOS NO QUE SE REFERE À (RE) CONSTRUÇÃO DA IDENTIDADE SOCIAL DE RAÇA, GÊNERO E CLASSE SOCIAL

A escola cumpre um papel muito importante na vida do aluno, embora não seja a única responsável pelas transformações da sociedade, pois vem orientada muitas vezes para a manutenção das estruturas sociais e econômicas dominantes, que impedem a própria transformação. Ainda assim, tem a possibilidade de contribuir positivamente na formação identitária dos educandos. Partindo desse pressuposto, fazemos uso das contribuições de Paulo Freire (2006):

A conscientização implica, pois, que ultrapassemos a esfera espontânea de apreensão da realidade, para chegarmos a uma esfera crítica na qual a realidade se dá como objeto cognoscível e na qual o homem assume uma posição epistemológica. (2006, p. 30).

Por isso, quanto mais o homem se tornar capaz de refletir sua realidade, maior condição terá de agir sobre ela e, assim, o trabalho educativo será expressão da consciência crítica.

Os Parâmetros Curriculares Nacionais (PCN-1998) e as Orientações Curriculares para o Ensino Médio (OCEM) atribuem a língua estrangeira em conjunto com as demais disciplinas do currículo escolar. Nesse sentido, o desafio de ensinar uma língua estrangeira como disciplina curricular no atual contexto educacional implica necessariamente a elaboração de atividades que aliem o estudo do idioma ao acesso a manifestações culturais de outros povos.

A visão do livro se insere na perspectiva do processo ensino-aprendizagem entendido como sociointeracionismo sociodiscursivo, para atender ao disposto pelas OCEM:

[...] os objetivos a serem estabelecidos para o ensino de Língua Espanhola no nível médio devem contemplar a reflexão - consistente e profunda - em todos os âmbitos, em especial sobre o "estrangeiro" e suas (Inter) relações com o "nacional", de forma a tornar (mais) consistentes as noções de cidadania, de identidade, de plurilinguismo e de multiculturalismo, conceitos esses relacionados tanto à língua materna quanto à língua estrangeira. (BRASIL. Orientações Curriculares para o Ensino Médio, 2006, p. 149). 
Dessa maneira, a Língua estrangeira (LE, de ora em diante) contribui na formação humana dos alunos, preparando-os para a sociedade complexa em que vivemos, atendendo ao artigo segundo a Lei de Diretrizes e Bases $35 \mathrm{da} \mathrm{LDB} / 96$, que atribui finalidades ao ensino médio acerca de autonomia intelectual bem como pensar criticamente. O desafio no ensino da língua será com que o aluno desenvolva sua capacidade de pensar e atuar, de maneira crítica e autônoma, na sociedade em que está inserido.

[...] não se pode esquecer que dominar uma língua estrangeira supõe conhecer, também e principalmente, os valores e crenças presentes em diferentes grupos sociais, que certamente entrarão em contato [...] ter consciência, entender e aceitar esses novos valores e crenças presentes em diferentes grupos sociais, distintos dos nossos em muitos aspectos, é imprescindível para que se efetive o que se vem chamando de comunicação intercultural. (OCEM, 2006, p. 148).

Essa citação reforça a necessidade de trabalhar na língua estrangeira a reflexão sobre os diferentes grupos sociais. Os PCNs (1998, p.49) afirmam que "não faz sentido, por exemplo, considerar o espanhol somente como a língua da Espanha [...]”. Se existem outros países que falantes de espanhol como língua oficial e que possuem sua diversidade cultural que merece ser respeitada. Inclusive um país que fica na África, Guiné Equatorial, e não é citado em muitos LD. As relações étnico-raciais dentro da escola são moldadas pela cultura. A partir do momento em que o monoculturalismo reina nos currículos escolares, o silenciamento de outras culturas não dominantes acaba por se impor (ARROYO, 2007, p. 128).

Essa realidade aponta que "[...] o sistema escolar esteja contaminado por estereótipos e preconceitos, sobretudo contra as culturas, religiosidades, memórias, identidades étnico-raciais e contra os grupos que as representam" (GOMES, 2010). A educação brasileira desenvolve atividades baseada na cultura eurocêntrica e que acaba por discriminar e excluir pessoas negras.

\section{Alguns apontamentos SOBRe as IMAgENS CONTIDAS NO LD DE ESPANHOL, $1^{0}$ LIBRo Do ENSINO MÉDIO, DA COLEÇÃo SÍNTESIS (IVAN MARTÍN, 2010)}

RAÇA

Entendendo que a desigualdade também é perceptível no ambiente educacional, quando há tratamentos diferenciados entre brancos e negros, materiais didáticos utilizados em que não valorizam as diferentes raças e culturas, faremos uso do termo raça a partir dos estudos de Gomes (2005, p. 43), como uma construção social, histórica, cultural e plural.

Ao trazer à discussão o termo raça utilizado pelo Movimento Negro e alguns sociólogos, Gomes (2005, p. 45) aponta que esses utilizam o termo "raça" com uma interpretação de 
"dimensão social e política do referido termo". Nesse sentido, concordamos com Gomes (2005, p. 46), quando afirma que "vivemos em um país com uma estrutura racista onde a cor da pele de uma pessoa infelizmente é mais determinante para o seu destino social do que o seu caráter, a sua história, a sua trajetória”. Ou seja, as pessoas são rotuladas para ocupar determinados espaços na sociedade e, infelizmente, a cor de pele ainda tem sido um fator determinante para quesito admissional, relacionamentos, padrão de beleza, etc. Por essa razão, discutir a respeito de raça no espaço escolar é fundamental e, a respeito dessas discussões a partir do livro didático, temos as contribuições de Silva (1989), em que destaca:

O livro didático ao vincular estereótipos que expandem uma representação negativa do negro e uma representação positiva do branco, está expandindo a ideologia do branqueamento, que se alimenta das ideologias, das teorias e estereótipos de inferioridade/superioridade raciais que se conjugam com a não legitimação pelo Estado, dos processos civilizatórios indígenas e africanos, entre outros, constituintes da identidade cultural da nação" (SILVA, 1989, p. 57).

As representações dos negros no LD estão normalmente carregadas da ideologia do grupo dominante. De acordo com Dambros (2016, p. 73-74) há uma disparidade em que o branco aparece mais vezes representado que o negro, remete ainda que o branco aparece exercendo atividades diferenciadas do negro, inclusive exercendo funções/atividades que demonstram diversos papeis sociais, enquanto que para o negro, essas atribuições são limitadas. Assim o combate a qualquer tipo de conjunto de ações e reflexões que contrariem os direitos humanos passa a ser, na sociedade contemporânea, responsabilidade da escola. É imprescindível que seja analisado de que forma está sendo representada a Lei 10.639 de 9 de janeiro (2003) no LD. Essa Lei que inclui o ensino de História e Cultura Afro-brasileira no currículo do Ensino Básico foi um resultado de um movimento de pressões feitas por pesquisadores e movimentos sociais negros para mudanças na forma como a população negra brasileira vem sendo tratada no campo educacional.

A análise da presença de negros e brancos entre os personagens das ilustrações dos livros didáticos é importante para destacarmos o quanto os critérios dos editais dos livros didáticos, conforme definidos pelo Ministério da Educação (MEC), conseguem garantir que parte da diversidade étnico-racial brasileira esteja presente neste material, considerando a atual concentração de livros indicados nas mãos de poucos grupos editoriais.

\section{EM RELAÇ̃̃o AO GÊNERO NO LD}

Segundo Ferreira (2014, p. 246), temos atualmente no Brasil uma "acalorada discussão acerca da chamada ideologia de gênero”. Entendemos que essas discussões perpassam 
diversos espaços sociais, inclusive a escola e, nesse contexto, mostra-se relevante e atual por levar a discussão sobre gênero e raça/etnia para um instrumento central da educação formal: os livros didáticos.

A maioria dos livros didáticos de língua estrangeira representam mulheres e homens na família, no mundo do trabalho e no esporte. Em relação às representações de família, normalmente se mostram conservadores, no sentido de que trazem imagens tradicionais: não representam famílias de pais separados, relacionamentos entre pessoas do mesmo sexo ou pais casados mais de uma vez.

Os homens são geralmente apresentados como os "provedores do lar" e autoridades máximas da família, enquanto às mulheres cabem os papéis de boa esposa e mãe dedicada (PEREIRA, 2007). No entanto, a própria escola pode reproduzir e legitimar a heteronormatividade presente na sociedade, bem como a distinção de papéis sociais tidos como masculinos e femininos.

\section{Classe Social}

As aulas de línguas estrangeiras são instrumentos de construção de sentidos que vão além da mera aprendizagem da língua, estabelecendo uma relação entre a linguagem e as questões sociais de poder, de identidades e de diversidade.

De acordo com Norton e Toohey (2011), estudos com foco em identidades de classe social, que analisem desigualdades no acesso à educação em línguas, precisam ainda ser mais enfatizados, tendo em vista o contexto de iniquidades que a globalização nos apresenta. Santos (2013) discute como identidades de classe social são construídas em um livro didático adotado em uma instituição pública de ensino de línguas no Brasil. Suas análises apontam que o livro didático reproduz estereótipos no que se refere a aspectos como uso de serviços, lazer e profissões.

Quanto ao uso de serviços, no livro há menção àqueles como saúde e atendimento médico, transporte, educação e serviço de creches para crianças apenas no setor privado; serviços para pessoas que devem e podem pagar. As pessoas que aparecem no livro fazendo uso desses serviços explicam o quanto pagam por eles, como o serviço é prestado, mas não há menção a como a esfera pública atende à população em relação aos mesmos aspectos, o que dá a entender que falantes de inglês não usufruem dos serviços sociais prestados pelo Estado, pois podem pagar por uma rede privada que os atenda (Santos, 2013, p. 164-165).

Há uma elitização do lazer nos livros didáticos, já que existe uma valorização dos destinos turísticos tidos como famosos, que oferecem experiências de viagem de alto custo, segundo Dias; Mastrela-de-Andrade (2014). Ainda segundo as autoras, o Brasil carece de uma política 
estruturante do ensino de línguas, que propicie acesso justo a seus cidadãos e, ainda, que a sala de aula precisa ser pensada como um espaço de possibilidades.

\section{Apontamentos Sobre o Livro Síntesis}

O manual didático é composto de 184 páginas, está dividido em oito capítulos e acompanhado de um CD de áudio que contempla a parte auditiva da obra, com orientações sobre o desenvolvimento das atividades. Ao final de cada capítulo, contém uma revisão do conteúdo com atividades e questões de vestibulares relacionados ao tema estudado para averiguar a aprendizagem.

O LD propõe a aprendizagem através das questões sociais que são do cotidiano do aluno, aproximando da realidade por meio da linguagem não verbal, como ilustrações, fotos, desenhos, gravuras, ícones, mapas, gráficos, diagramas, fundos coloridos que ajudam na compreensão e produção do sentido.

Encontramos dois artigos sobre a análise deste LD: um sobre "Os gêneros textuais no livro didático Síntesis de língua Espanhola”, no qual os autores, José Rosamilton de Lima e Charles Albuquerque Ponte, analisaram que o Livro Didático Síntesis é um manual relevante para aprendizagem do aluno por oferecer uma proposta por meio de textos com uma boa diversidade de gêneros, adequados aos alunos, de forma a possibilitar situações reais de comunicação. O segundo artigo "Análise do livro didático de Espanhol para o Ensino Médio" mostra uma análise do $2^{\circ}$ Libro do Ensino Médio, no qual o autor José Maria Maciel Lima apresenta de forma geral que o LD faz uma abordagem dos conteúdos em uma perspectiva social, pela qualidade, organização e articulação dos conteúdos, pelo tipo de abordagem da língua - considerando a língua em seu pleno funcionamento, valorizando a diversidade cultural e linguística. Desse modo, a diversidade do aporte teórico torna a obra um referencial relevante para os estudos da linguagem nesta etapa de ensino.

O presente artigo tem um olhar sobre a representatividade através também das representações em relação à raça, gênero e classe social, pois:

No livro didático a humanidade e a cidadania, na maioria das vezes, são representadas pelo homem branco e de classe média. A mulher, o negro, os povos indígenas, entre outros, são descritos pela cor da pele ou pelo gênero, para registrar sua existência. (SILVA, 2005, 21).

Começando pelas páginas de abertura, o livro apresenta algumas perguntas gerais que têm a finalidade de motivar a realizar as atividades propostas e, ao terminar de estudar todos os capítulos, o aluno responda todas as questões. Juntamente estão as imagens dos assuntos que serão abordados nos capítulos e três delas chamam a atenção, pois podemos perceber que 
o livro abordará as diversidades culturais, de gênero e de raça, sendo uma imagem de uma famosa cantora argentina, de uma mulher negra e um calendário Asteca.

Na introdução do tema, o livro apresenta algumas informações sobre a língua espanhola e os povos falantes do idioma, com um gráfico das línguas mais faladas no mundo, seguido de um mapa com os países que falam língua portuguesa e língua espanhola. O objetivo é que os estudantes conheçam a existência das variantes linguísticas e da importância cultural de cada um dos países em que o idioma é língua oficial. Tal aproximação visa a promover uma postura respeitosa, que sempre deve ser adotada quando se dispõe a estudar a língua de outros povos.

Para exemplificar a diversidade cultural, há uma imagem da pintora mexicana Frida Kahlo "Mundo real danza al sol", mostrando as manifestações culturais de alguns povos que se expressam em espanhol. Para complementar, apresenta um áudio de um poema de Eduardo Galeano na voz de um argentino, um cubano, um mexicano e um espanhol, mostrando as diferenças de acento de cada país que fala espanhol e valorizando a diversidade cultura e linguística. Conforme a sugestão da OCEM quanto à abordagem de temas relevantes para a ampla formação do/da estudante, considerando as diferenças e especificidades locais/regionais.

No primeiro capítulo, há uma foto da cantora Mercedes Sosa, mais uma vez uma mulher sendo representada, que foi um símbolo da resistência contra as ditaduras latino-americanas com canções de protesto, pois teve uma atuação marcante durante a ditadura militar argentina, entre 1976 e 1983, e acabou exilada na Europa. Todos os capítulos são introduzidos com uma imagem e depois um diálogo com áudio. No final do primeiro capitulo, intitulado "Quién soy" o livro apresenta uma ilustração de uma mulher africana, juntamente com um texto que fala da origem dos seres humanos na África. Há uma crônica poética de Eduardo Galeano (p.23) que trata sobre racismo e seus entraves de uma forma reflexiva da composição étnica racial diversa, heterogênea da humanidade, sem hierarquizar ou sobrepor povos e culturas. No capítulo não há exercícios sobre a crônica, no entanto há uma proposta de debate no manual do professor (p.21) com nove questões.

$\mathrm{Na}$ abertura do capítulo sete, que fala sobre Família, o livro mostra uma imagem de uma família negra com muitas pessoas, podendo ser avós, tios, primos, filhos, pais, etc. (p. 121). O livro traz um diálogo que pede para os alunos refletirem sobre os diversos modelos de família, que têm se tornado mais abertos, pois, com as constantes mudanças sociais, podem ser encontrados os mais variados tipos de família, questionando alguns estereótipos relacionados a esse conceito. Essas diversas composições familiares representam um avanço por não fixar o modelo tradicional de família, composto somente por mãe, pai e filhos, e relacionam as identidades negras e de classes sociais às concepções de mundo mais inclusivas. Conforme Jovino (2015) comprova em suas pesquisas, que a representação de identidades negras em livros quase inexiste, no entanto, esta imagem é considerado um avanço na cultura visual do contexto educacional, pois permite a identificação positiva de identidade negra, através da visão da família negra empoderada e feliz. 
Em relação à classe social, o livro apresenta imagens juntamente com diálogos que são do cotidiano dos alunos e alunas. Em um exercício de vocabulário de descrição física de pessoas (p.115), são apresentadas características físicas e profissão de um homem negro. Sendo uma representação positiva na construção de identidade por trazer uma figura negra masculina exercendo a profissão de advogado, que é considerada uma profissão de prestígio social, desconstruindo as representações estereotipadas nas profissões ligadas ao uso da força, por exemplo. Essa representação pode colaborar na construção da autoestima dos alunos negros ao retratar uma realidade positiva diferente da que normalmente é representada nos livros didáticos em geral sobre profissões e classes social de negros e negras.

O capítulo quatro apresenta reflexão de consumo responsável, no capítulo seis, discute-se sobre a influência da mídia na construção das preferências relativas à moda. O capítulo oito, por exemplo, trata de vários tipos de moradias com o objetivo de refletir se todas as pessoas têm uma moradia digna e sobre as desigualdades sociais existentes no país.

O LD analisado apresenta 101 imagens, sendo 60 de mulheres, dentre as quais 14 são negras, e 41 de homens, dentre os quais 14 são negros.

Quadro 1: Representação de imagens de homens brancos x negros e mulheres brancas x mulheres negras

\begin{tabular}{|c|c|c|c|}
\hline Atributos & Branco & Negro & Total \\
\hline Homem & $27(65,85 \%)$ & $14(34,15 \%)$ & $41(100 \%)$ \\
\hline Mulher & $46(76,67 \%)$ & $14(23,33 \%)$ & $60(100 \%)$ \\
\hline Total & $73(72,28 \%)$ & $28(27,72 \%)$ & $101(100 \%)$ \\
\hline
\end{tabular}

Fonte: MARTIN (2011).

Podemos observar que em relação à questão de gênero predomina a figura feminina neste LD, ao contrário de muitos outros. Para comparar, encontramos uma análise sobre a representação e identidade racial no livro didático de espanhol Enlaces (OSMAN et al., 2013), feita por JOVINO e COUTO (2015) em uma unidade didática em que as autoras mostraram que, quanto aos aspectos qualitativos, foram encontradas 312 imagens de pessoas brancas para 89 de pessoas negras.

No recorte por gênero, observam-se 152 homens brancos para 33 homens negros e 127 mulheres brancas para 56 mulheres negras. Pode-se considerar que neste livro didático analisado há representatividade nas imagens em relação à raça, gênero e classe social. No entanto, ENEVAN (2016), em sua dissertação, fez uma análise em relação aos temas e aos exercícios relacionados às imagens de pessoas negras e constatou que as representações têm poucos textos e exercícios, sendo que $58 \%$ dos temas são excludentes e marginalizam as identidades negras representando-as de maneira estereotipada. Os estereótipos clássicos encontrados neste LD são: trabalhador braçal, carente social e africano. 
Segundo as Orientações Curriculares para o Ensino Médio (OCEM), o LD precisa apresentar uma proposta didático-pedagógica que valorize o papel da língua estrangeira na formação de indivíduos dotados de "Consciência Social", criatividade, mente aberta para conhecimentos novos (2006, p.90), contribuindo para construção de uma nova forma de pensar e ver o mundo.

\section{CoNSIDERAÇõES FINAIS}

A identidade pode ser construída por meio da fotografia, por ela ser também uma representação, posto que passe por escolhas, processos que decidem o resultado. É também uma representação da representação, pois há que se considerar todo o processo que envolve a escolha e seleção das imagens para fazerem parte do LD (cortes, vetos, trocas, etc. que envolvem o processo de editoração e revisão).

O LD Síntesis, aqui analisado, apresenta aspectos positivos e um avanço nas formas de representar as identidades sociais de negros e negras nos livros didáticos do PNLD, pois algumas pessoas negras aparecem exercendo profissões e atividade de prestigio social. No entanto, os espaços conquistados pelas pessoas negras encontradas nessa coleção ainda são menores em relação aos brancos, não atingindo o nível de igualdade de representação que seria justa. Sendo constatado, portanto, que neste LD predominam as pessoas brancas, a branquitude como norma. Conforme Ferreira (2014), essa postura nos livros didáticos é um exemplo da divisão racial no ambiente escolar e do racismo velado na escola.

Em relação ao gênero, a representatividade dominante presente no LD é de mulheres. As imagens e os textos trabalham as questões sociais acercando-se dos discentes. As imagens estão de forma alguma em conformidade com o que pede a lei 10.639/03, ressaltando a cultura negra africana, a historicidade do povo negro e enaltecendo a raça negra.

Como mencionam os PCN (1998) dentre os objetivos da língua estrangeira, o aluno deve utilizar as habilidades linguísticas de modo a poder atuar em situações diversas. Ele deve ter acesso a bens culturais da humanidade construídos em outras partes do mundo, assim como construir consciência linguística e crítica dos usos que se fazem da língua que está aprendendo. Além disso, o referido documento acrescenta que o papel educacional da língua estrangeira no currículo da educação básica é a sua contribuição como um todo, que vai muito além da aquisição de habilidades linguísticas.

Tentando responder à pergunta "Qual a relevância das representações visuais em relação à raça e gênero e classe social encontradas em um livro didático de Espanhol?”, pode-se dizer que a representação visual deve fazer parte, portanto, das reflexões sobre os processos de construção de conhecimento escolar, atentando para as diferentes soluções de interlocução que a mediação pela imagem propõe para a observância de seus códigos e a violação destes, 
suas implicações discursivas e para a compreensão de que sejam os processos cognitivos desenvolvidos para e através da leitura de imagens.

Este artigo mostra que as representações visuais em relação à raça e gênero e classe social no livro de espanhol ainda são precárias, por isso torna-se tão importante que haja um olhar para o livro didático para que possa ser descontruído o racismo institucional, camuflado nos silenciamentos das opressões desde a elaboração de políticas educacionais até o interior das instituições de ensino.

É necessário que verifique-se se os materiais produzidos no PNLD estão de acordo com os discursos sobre identidades que estão "sendo veiculados no ambiente escolar, ainda mais na escola pública, onde o acesso à informação é de caráter mais amplo, ou seja, atinge mais uma diversidade de segmentos sociais, culturais e étnico-raciais" (JOVINO, 2014, p. 126). Desde um olhar para a linguística aplicada, Ferreira (2014) assevera que "escrever e pensar sobre livros didáticos de língua estrangeira no Brasil requer refletir de como era e como é atualmente o ensino de língua estrangeira no Brasil até então e qual é o papel do livro didático" (p. 93).

O docente precisa reconstruir e valorizar os aspectos históricos e culturais onde os conteúdos trabalhados sejam adequados com a realidade do nosso país para que o/a aluno/a construa sua própria identidade. Isso não significa deixar a cultura europeia de lado e trazer somente a cultura africana, mas sim entrelaçar os ensinamentos para a pluralidade presente na história do Brasil. Nesse sentido, Ferreira (2014, p.49) reforça que cabe ao professor elencar um livro didático que melhor convenha à sua realidade, permitindo melhor adaptação, desde que esteja claro que isso nunca será uma alternativa mais satisfatória, tendo em vista a abrangência do PNLD e a consequente impossibilidade de cobrir a diversidade contextual do país como um todo.

Sugere-se que haja mais formação continuada para professores de línguas estrangeiras baseada nas reflexões etnicorraciais, de gênero e de classe social, para que esses possam identificar todo tipo de preconceito, discriminação e desigualdade nas páginas dos livros didáticos e assim lutar contra todo tipo de preconceito juntamente com seus alunos, para que juntos possam refletir sobre suas identidades.

\section{REFERÊNCIAS}

ARROYO, M. G. A pedagogia multirracial popular e o sistema escolar. In: GOMES, N. L. (org). Um olhar além das fronteiras: Educação e relações raciais. Belo Horizonte: Autêntica, 2007.

BRASIL, Ministério da Educação e Cultura do. Parâmetros Curriculares Nacionais. Língua Estrangeira. Brasília, 1998. 
BRASIL. Orientações Curriculares Para O Ensino Médio (OCEM). 2006. Linguagens, códigos e suas tecnologias/Secretaria de Educação Básica. Brasília, Ministério da Educação, Secretaria de Educação Básica. Conhecimentos de línguas estrangeiras, vol. 1, p.148.

BRASIL. Lei 10.639/2003. Estabelece a obrigatoriedade do Ensino de História e Cultura afroBrasileria e Africana. Brasília, Ministério da Educação, 2003.

DAMBROS, L. P. Construção das identidades sociais de raça com intersecção de classe nos livros didáticos de inglês do ensino médio aprovados pelo PNLDs de 2012 e 2015. 2016.164f. Dissertação (Mestrado em Linguagem, Identidade e Subjetividade) - Universidade Estadual de Ponta Grossa, 2016.

DIAS, R.S; MASTRELLA-DE-ANDRADE, M.R. Narrativas de Professores: Identidades Sociais de Raça e Classe no Processo de Ensino-Aprendizagem de Inglês. In: FERREIRA, A. J. (Org). Narrativas Autobiográficas de Identidades Sociais de Raça, Gênero, Sexualidade e Classe em Estudos de Linguagem. Campinas: Pontes Editores, 2015, p. 77-103.

ENEVAN, É.A.S. Um Olhar Sobre As Representações De Identidades Sociais De Raça: Análise De Livros Didáticos Para O Ensino De Espanhol/Le. 2016. 207 f. Dissertação (Mestrado em Linguagem, Identidade e Subjetividade) - UNIVERSIDADE ESTADUAL DE PONTA GROSSA, Ponta Grossa, 2016.

FERREIRA, A. J. (Org.) As Políticas do Livro Didático e Identidades Sociais de Raça, Gênero, Sexualidade e Classe em Livros Didáticos. Campinas, SP: Pontes Editores, 2014

FERREIRA, A. J. (Org.) Narrativas Autobiográficas de Identidades Sociais de Raça, Gênero, Sexualidade e Classe em Estudos da Linguagem. 1ed. Campinas: Pontes Editores, 2015.

FREIRE, P. Pedagogia da esperança. $13^{a}$ ed. Rio de Janeiro: Paz e Terra, 2006.

GOMES, N. L. (Org). Diversidade étnico-racial e educação no contexto brasileiro: algumas reflexões. In: GOMES, N. L. Um olhar além das fronteiras: educação e relações raciais. Belo Horizonte: Autêntica, 2010. p. 97-109

JORGE, M. L. S. Livros didáticos de línguas estrangeiras: construindo identidades positivas. In: FERREIRA, A. J. (Org.) As Políticas do Livro Didático e Identidades Sociais de Raça, Gênero, Sexualidade e Classe em Livros Didáticos. Campinas, SP: Pontes Editores, 2014, p.73-87

JOVINO, I. S. (2014). Representação de negros e negras num livro didático de Espanhol: alguns apontamentos. In: FERREIRA, A. J. (org.). As políticas do livro didático e identidades sociais de raça, gênero, sexualidade e classe em livros didáticos. Campinas, SP: Pontes, p. 121-141.

JOVINO, I. S.; COUTO, L. P. Entre laços: representação e identidade racial num livro didático de espanhol. Muitas Vozes, v. 4, p. 43-62, 2015.

LIMA, J. R.; PONTE, C. A. Os gêneros textuais no Livro Didático Síntesis de Língua Espanhola. Entretextos (UEL), v. 14, p. 07-26, 2014. 
LIMA, J. M. M. Análise Do Livro Didático De Espanhol Para O Ensino Médio. 2017; Tema: Ensino de Língua Estrangeira. Revista Hispanista.

MARTIN, I. Síntesis: Curso de Lengua Española. Libro 1, Ensino Médio: Língua Estrangeira Moderna: Espanhol. Ed. Ática, São Paulo, 2011.

MUNANGA, K. (org.) - Superando o Racismo na Escola. $2^{\text {a }}$ edição. Ministério da Educação, Secretaria da Educação e Diversidade, 2005.

NORTON, B.; TOOHEY, K. Identity and language learning. KAPLAN, Robert B. (Ed.). The Oxford handbook of applied linguistics. Oxford e New York: Oxford University Press, p.115$123,2002$.

PEREIRA, A. L. Representações de gênero em livros didáticos de língua estrangeira: reflexos em discursos de sala de aula e relação com discursos gendrados que circulam na sociedade. 2007. 280p. Tese (doutorado) - Universidade Estadual de Campinas, Instituto de Estudos da Linguagem, Campinas, SP.

SANTOS, M. S. A construção de identidades no livro didático de língua estrangeira: uma perspectiva crítica. 239 f. Dissertação (Mestrado em Linguística Aplicada) - Universidade de Brasília. Brasília, 2013.

SILVA, A. C. A discriminação do negro no livro didático. Salvador: CED - Centro Editorial Didático e CEAO - Centro de Estudos Afro - Orientais, 1995, p 34; 47; 135.

SILVA, A. C. Desconstruindo a discriminação do negro no livro didático. Salvador: EDUFBA, 2001, p 14; 16; 19; 51; 58.

SILVA, A. C. As transformações da representação social do negro no livro didático. 2003. Disponível em: <HTTP:www.uneb.br/ascom/jmcnet/jo7/jo7cltm>. Acesso em: 20 abr. 2019.

SILVA, A. C. A desconstrução da discriminação no livro didático. In: MUNANGA, K. Superando o Racismo na Escola. Brasília: Ministério da Educação, Secretaria da Educação Continuada, Alfabetização e Diversidade, 2005.

SILVA, P. B. G. Aprendizagem e ensino das Africanidades brasileiras. $2^{\circ} \mathrm{Ed}$. In: Munanga, Kabengele (org.) Superando o racismo na escola. Ministério da Educação Continuada, alfabetização e diversidade, 2005 (23; 155; 172).

TELLES, J.A. “É pesquisa, é? Ah, não quero, não, bem!” Sobre pesquisa acadêmica e sua relação com a prática do professor de línguas. Linguagem \& Ensino, v.5, n.2, p.91-116. 2002.

VYGOTSKY, L. Pensamento e Linguagem. Martins Fontes. 2000.

Recebido para publicação em 5 de Janeiro de 2020. Aceito para publicação em 26 de Fevereiro de 2020. 